\title{
Bienestar psicológico e involucramiento religioso en estudiantes universitarios de Lima
}

\author{
Psychological well being and religious involvement in university students \\ in Lima
}

\author{
Juan Carlos Escudero Nolasco ${ }^{1}$ \\ Policlínico Peruano Japonés
}

Recibido: $02-10-17$

Aceptado: $21-11-17$

\begin{abstract}
Resumen
El objetivo del estudio fue establecer la relación entre el bienestar psicológico y el involucramiento religioso, así como, encontrar diferencias en el bienestar psicológico entre las distintas formas de involucramiento religioso. La muestra estuvo constituida por 297 estudiantes universitarios de la facultad de psicología de una universidad pública de Lima Metropolitana. Para la recolección de datos se utilizó la Escala de bienestar psicológico para adultos (BIEPS) adaptada al contexto peruano y un cuestionario sobre involucramiento religioso elaborado por el autor. Los resultados evidenciaron que no existe relación entre el bienestar psicológico y el involucramiento religioso, sin embargo, se encontró que el grupo de alto involucramiento religioso que mantiene participación activa en grupos religiosos presenta mayor bienestar psicológico general y en el componente proyectos de forma significativa, en comparación a los que mantienen otras formas de involucramiento religioso.

Palabras Clave: bienestar psicológico; involucramiento religioso; religiosidad; estudiantes universitarios.
\end{abstract}

\begin{abstract}
This study aims to establish the relationship between the psychological well being and the religious involvement and to find out the differences in the psychological well being among the different forms of religious involvement. The sample was composed of 297 students from a public university in Lima city. The psychological well being scale for adults (BIEPS, for its Spanish acronym) adapted to the Peruvian context was used to collect the data and a questionnaire created by the author. The results showed that there was no relationship between the psychological well being and the religious involvement. However, we found out that the psychological well being is significantly higher in the group with high religious involvement, which has active participation in religious groups, as well as in the projects component, in contrast to students with other levels and types of religious involvement.
\end{abstract}

Key words: psychological well being; religious involvement; religiosity; university students.

1 Psicólogo del Policlínico Peruano Japonés, juancescuderon@gmail.com

(C) Los autores. Este artículo es publicado por la Revista de Investigación en Psicología de la Facultad de Psicología, Universidad Nacional Mayor de San Marcos. Este es un artículo de acceso abierto, distribuido bajo los términos de la licencia Creative Commons Atribucion - No Comercia_Compartir Igual 4.0 Internacional. (http://creativecommons.org/licenses/by-nc-sa/4.0/) que permite el uso no comercial, distribución y reproducción en cualquier medio, siempre que la obra original sea debidamente citada. 
La religión ha sido parte de la experiencia humana desde culturas antiguas, encontrándose prácticas religiosas anteriores al 3000 a.c. (Valiente y García, 2010), manifestadas por la creación de tótems asociados al culto a los ancestros o la fecundidad(Rodríguez, Fernández, Pérez y Noriega, 2011).Pasando a lo largo de los siglos por diferentes influencias entre las que se puede mencionar a San Agustín y San Gregorio Magno, así como, por las reformas de las órdenes religiosas de las escuelas flamenca y española, además, de diversas polémicas en especial a confrontarse las visiones científicas con interpretaciones bíblicas (Arias, Masías, Muñoz y Arpasi, 2013; Florenzano, 2010).Las religiones se han ido diversificando y actualmente se fundan de dos a tres movimientos religiosos diarios, registrándose cerca de diez mil religiones (Valiente y García, 2010).

En cuanto a la reflexión psicológica, inicialmente se buscó separar el conocimiento científico delo religioso, considerando que la religión, al ocuparse de problemas de fe, estaba ligada a la filosofía y no a la ciencia (Uresti, Ramírez y Caballero, 2011).El punto de inflexión respecto a lo anterior lo dio William James, quien incluye el fenómeno religioso como realidad de estudio científico (Valiente, 2013). En su obra La variedad de la experiencia religiosa de 1902, James distingue entre religión como institución y como práctica personal, y entre religiosidad sana y enfermiza, y señala que son factores emotivo, cognitivo y conductuales los que operan en las experiencias religiosas (Quiceno y Vinaccia, 2009).Desde otra perspectiva, la religión es concebida por Freud como una neurosis obsesiva universal, y sustenta la existencia de raíces psicopatológicas del fenómeno religioso (Valiente, 2013).En 1959 se instala la división 36 de la American Psychiatric Association, denominándose Asociación Católica Americana de Psicología. En 1970 se renombró como Psicólogos Interesados en Temas Religiosos, y posteriormente en 1992 pasó a llamarse Psicología de la Religión (Nervi, 2011).

La psicología de la religión estudia de las constantes psicológicas de la religiosidad, que indaga sobre la realidad humana donde aparece la fe, percibida como una revelación divina y busca analizar críticamente las realidades religiosas (Stollberg, 1979; citado por Garcés, 1985). La religiosidades la forma subjetiva de apropiación de la religión, es decir su expresión psíquica y personal (Grifa y Moreno, 1999) y el grado en que una persona cree, sigue y la practica (Jiménez, 2005). Por su parte, Clark, plantea dividir el comportamiento religioso en tres: el primario, como la genuina experiencia interior, la cual que conduce a una actividad dirigida a armonizarla vida con la deidad; el secundario, que anteriormente pudo haber sido primario, pero que se trastocado en rutinario y habitual; y el terciario, como la simple aceptación de rutinas religiosas dadas por otros (Drakeford, 1980).

Actualmente existe amplia literatura científica sobre la religiosidad asociándola con estilos de afrontamiento, suicidio, depresión, conductas sexuales, psicosis, ansiedad y uso de sustancias, entre otros (Reyes, Rivera, Ramos, Rosario y Rivera, 2014).Uno de los tópicos de mayor interés es la asociación entre la 
religiosidad con el bienestar psicológico, definida esta última como una dimensión evaluativa, que tiene que ver con la valoración del resultado logrado con una determinado forma de haber vivido (Casullo y Castro, 2000).

Por su parte, la investigación científica acerca del bienestar empieza a finales del siglo XX, antecedido por pensamientos de filósofos de la antigüedad, tales como Platón, Aristóteles, Confucio y Séneca; y de reflexiones derivadas de tradiciones espirituales como el cristianismo o el budismo (Vielma y Alonso, 2010).En los años 70 el estudio de la felicidad pasa al terreno psicológico, abriéndose dos grandes vertientes, derivadas de tradiciones griegas, la hedónica y la eudaemónica, a los que corresponden los conceptos de bienestar psicológico y bienestar subjetivo. La tradición hedónica tiene en Epicuro a su máximo representante, según quien el propósito de la vida es experimentar la mayor cantidad de placer y la felicidad sería una suma de momentos placenteros. El concepto predominante sobre esta tradición es el bienestar subjetivo, que incluye las dimensiones la cognitiva y emocional. Generalmente se le llama felicidad al bienestar subjetivo experimentado al sentir más emociones agradables y menos desagradables, el estar comprometido en actividades interesantes y sentirse satisfecho con la vida que uno lleva (González, 2004).Respecto a la tradición eudemónica, Aristóteles define a la felicidad (eudaemonia), como los sentimientos derivados de un comportamiento que se dirige de forma consistente con el desarrollo de su verdadero potencial, asimismo, la felicidad está en la expresión de la virtud, refiriéndose no a un estado de satisfacción transitoria, sino el conjunto de una vida lograda (Romero, García y Brustad, 2009).

Entre quienes han estudiado el crecimiento personal se puede mencionar a Maslow y su planteamiento sobre la autoactualización, Rogers y sus noción sobre el funcionamiento humano pleno, y a Allport con su concepto acerca de la madurez(Romero, García y Brustad, 2009).Waterman (1993; citado por Romero, García y Brustad, 2009), fue uno de los primeros en identificar esta forma de bienestar psicológico, la cual denominó sentimientos de expresividad personal. Los cuales están relacionados a experiencias de gran implicación con las actividades que se realizan, sentirse vivo y realizado, asumir la actividad como algo que nos llena, de una impresión encontrar el sentido en lo que se hace. Por su parte, Castro (2009) realiza una revisión acerca de los diferentes modelos teóricos del bienestar psicológico y las divide en:

Las teorías universalistas. La satisfacción se logra al alcanzar objetivos o haber satisfecho necesidades básicas. Llegar al bienestar resultará de alcanzar distintos objetivos, para diferentes personas, de acuerdo a la etapa de la vida.

Los modelos teóricos situacionales. La suma de momentos felices da como resultado la satisfacción de las personas. Se da elevada importancia a las circunstancias que las personas tienen que vivir. 
Las teorías de la adaptación. Frente a eventos muy estresantes las personas tienden a adaptarse y volver a su nivel de bienestar previo. Los sistemas reaccionan de forma automática a las desviaciones del nivel de adaptación actual, permitiendo que el impacto del evento se diluya.

Las teorías de las discrepancias. El bienestar se explica por la comparación que hacen las personas entre sus estándares personales y el nivel de sus condiciones actuales.

De acuerdo a Casullo (2002) dentro de las teorías universalistas se encuentra el Modelo Multidimensional del Bienestar Psicológico de Ryff. Este autor critica los estudios donde se considera el bienestar psicológico como falta de malestar o de trastornos mentales, lo cual ignora las teorías de autorrealización, el ciclo de vida, el funcionamiento mental óptimo y el significado de la vida. Asimismo, señala la multidimensionalidad del constructo (Ryff y Keyes, 1995; citados por Casullo, 2002).Según su perspectiva, el bienestar psicológico es un concepto que abarca más que la mera estabilidad de afectos positivos a través de los años. Ryff elaboró un modelo compuesto por seis dimensiones (Díaz, et al., 2006):

La auto-aceptación. El intentar sentirse bien consigo mismo, incluso cuando se es consciente de las limitaciones.

La capacidad de mantener relaciones positivas. Mantener relaciones estables y tener amigos en quienes confiar. El aislamiento social o la pérdida de apoyo social se asocian al riesgo de padecer alguna enfermedad.

La autonomía. Preservar la individualidad en contextos distintos, mantener las convicciones, independencia y autoridad personal.

El dominio del entorno. Habilidad para elegir o generar ambientes favorables para satisfacer las aspiraciones y necesidades.

Los sentimientos positivos dirigidos hacia el crecimiento personal. Búsqueda del desarrollo del propio potencial y fortalecimiento de las capacidades.

La creencia de propósito y el sentido de la vida. Tener objetivos claros y realistas que den significado a las experiencias, es decir un propósito de vida.

En cuanto a la relación entre ambos conceptos expuestos, James y Wells (2003; citados por Simkim, 2010) indican que esta relación depende de dos mecanismos cognitivo conductuales. En primer lugar, las creencias religiosas, como esquemas, brindan modelos mentales generales que son base para la evaluación de los sucesos vitales; y en segundo lugar, estas creencias proveen una base para la autoregulación del proceso de pensamiento, los cuales pueden ser o no beneficiosos, dependiendo de su forma y contenido. Por su parte, Cyrulnik (2002) ha señalado que la religión ofrece un camino con sentido, encuentros amistosos, 
la posibilidad de compartir una trascendencia y un factor de cohesión grupal. Mientras que Hill y Pargament (2003; citados por Salgado, 2014) mencionan que las creencias espirituales brindan apoyo y estabilidad en las crisis, otorgan la sensación de un sentido último, inclusive en situaciones estresantes, facilitando una filosofía unificadora de la vida.

En cuanto a las investigaciones al respecto, Vargas y Martínez (2015) encontraron niveles más bajos de abuso del alcohol en adolescentes mexicanos que valoraban más a la iglesia y acudían a esta, en compañía de padres o amigos. Ceballos, Pérez, Rosado y Rodríguez (2014) en estudiantes universitarios colombianos, encontraron relaciones significativas y negativas entre la religiosidad con algunas conductas de riesgo, asumiéndola como factor protector. Sardín (2012) extrayendo datos de la Encuesta de la Deuda Social Argentina (EDSA),hallóque el practicar la mayoría de las religiones se relacionaa mayor satisfacción. Ferre, Gerstenblüth y Rossi(2008)a partir de los datos de una encuesta nacional de opinión pública en Uruguay, concluyeron que quienes acuden más a servicios religiosos presentan mayor probabilidad de sentirse satisfechos con susvidas. Finalmente, Koenig, McCullogh y Larson (2001; citados por Salgado, 2014) luego de un análisis crítico y sistemático de más de 1200 estudios empíricos y 400 revisiones encontraron que los beneficios que brindan la espiritualidad y la religiosidad son ayudar a la prevención, acelerar la recuperación y promover la tolerancia al padecimiento.

Es en el contexto del estado actual de investigación que se formula como problema general: ¿Existe relación entre el bienestar psicológico y el involucramiento religioso en estudiantes universitarios de Lima? Por consiguiente, se plantea como objetivo establecer la relación entre bienestar psicológico e involucramiento religioso, entendido este último como el grado en que una persona vivencia su religión como parte de su vida, concepto similar a la definición de Jiménez (2005) sobre religiosidad, como el grado en que se cree, sigue y practica la religión, y que también encuentra coincidencia con la división que hace Clark del comportamiento religioso. Además, se busca establecer a través de diversas comparaciones, las diferencias en el bienestar psicológico y sus dimensiones, según los niveles y formas de involucramiento psicológico.

\section{MÉTODO}

\section{Tipo y diseño de investigación}

El estudio presenta un enfoque cuantitativo, dado que utiliza la medición numérica y el análisis estadístico. Es correlacional, pues busca asociar variables mediante un patrón. El diseño es no experimental transaccional, pues que solo se observan fenómenos y los datos se recopilan en un momento único (Hernández, Fernández y Baptista, 2014). 


\section{Muestra}

La muestra fue constituida por 297 universitarios de la carrera de psicología mayores de 18añosde una universidad pública de Lima Metropolitana. El muestreo fue no probabilístico intencional, dado que la elección de la muestra no depende de la probabilidad sino que es el investigador quien lo decide basándose en su apreciación subjetiva sobre su representatividad (Hernández, et. al., 2014). En cuanto al sexo de los evaluados, el 63\% (187) son mujeres y el 37.0\% (110) varones.En relación a la procedencia el 92.9\% (276) son de Lima, mientras que el $7.1 \%$ (21) de provincia. En lo referido a las variables asociadas al involucramiento religioso, el 75.8\% (225) afirma creer en dios, el 44.8\% (133) manifiesta ser cristiano católico, mientras que el 13.8\% (41) cristiano no católico, el $62.3 \%$ (185) se considera parte de una religión, el 20.5\% (61) asiste con frecuencia a misas o reuniones religiosas y finalmente el 12.1\% (36) participan activamente en un grupo juvenil religioso.

\section{Técnicas e instrumentos de recolección de datos}

Para la recolección de los datos se coordinó previamente con los docentes de las aulas a evaluar, con quienes dieron su permiso se acordó una fecha y hora para la aplicación de los cuestionarios. En el momento de la aplicación se les entregó a los evaluados el consentimiento informado, señalándoles que su participación es voluntaria, confidencial y anónima, además que los datos recabados no se usarán para ningún propósito fuera de esta investigación. La recolección de datos se realizó mediante la observación indirecta a través de los siguientes instrumentos:

- Escala de Bienestar Psicológico (BIEPS). Desarrollada por Casullo y Castro (2000) en una muestra de 1270 adolescentes de tres regiones de Argentina. Sobre la base de las seis dimensiones propuestas por Ryff se redactaron 36 ítems. La validez de contenido por criterio de jueces encontró un $75 \%$ de acuerdo entre los jueces, quedando 20 ítems, con los cuales se realizó el análisis factorial por el método de componentes principales con rotación varimax. La solución final constó de 4 factores que explican el $50 \%$ de la varianza de las puntuaciones. En el proceso se eliminaron siete ítems, quedando conformada finalmente por trece. La confiabilidad por consistencia interna fue de 0.74.En Lima, Domínguez (2014) realizó el análisis psicométrico en una muestra de 222 universitarios de edades entre 16 a 44 años. La validez de constructo mediante análisis factorial confirmatorio, usando el método de máxima verosimilitud, indica un adecuado ajuste al modelo de Casullo y Castro (2000). De otro lado, la confiabilidad por consistencia interna arrojó un valor del alfa de Cronbach de 0.966.

- Ficha de involucramiento religioso. Cuestionario breve elaborado por el autor para fines de la presente investigación, presenta respuestas de opción múltiple que exploran las variables asociadas al involucramiento religioso: creencia en dios, pertenencia a una religión, religión que profesa, asistencia a 
misa y participación activa en grupos religiosos.. En cuanto a la confiabilidad por consistencia interna, el instrumento presenta un valor de Alfa de Cronbach de 0.726 . Asimismo, la validez de constructo por análisis factorial por rotación varimax indica que un solo factor, el involucramiento religioso, explica el $62.207 \%$ de la varianza.

\section{Procesamiento de datos.}

Se realizó mediante el programa estadístico para las ciencias sociales SPSS versión 22. Los datos descriptivos fueron frecuencias y porcentajes. En la estadística inferencial, se usó la prueba de normalidad de Kolmogorov Smirnov, determinando el uso de pruebas no parámetricas. Para la correlación se utilizó la Rho de Spearman, en la comparación múltiple la prueba Kruskal Wallis y en las comparaciones por pares la U de Mann Whitney.

\section{RESULTADOS}

\section{Niveles de bienestar psicológico}

En la tabla 1 se observa que a nivel general, la mitad de los estudiantes universitarios evaluados presentan alto bienestar psicológico $(51.9 \%)$, por el contrario, únicamente el 1.0\% mantiene bajo nivel de bienestar. Dicha proporción se repite en los cuatro componentes, pero cabe destacar que en el componente aceptación/control se presenta mayor proporción de evaluados en el nivel alto (65.3\%), indicando que predomina el bienestar psicológico como aceptación de uno mismo, autocompetencia y el control de las situaciones.

Tabla 1

Niveles de bienestar psicológico y sus dimensiones

\begin{tabular}{lllllll}
\hline \multirow{2}{*}{$\begin{array}{l}\text { Bienestar psicológico y sus } \\
\text { componentes }\end{array}$} & Bajo & \multicolumn{3}{c}{ Medio } & \multicolumn{3}{c}{ Alto } \\
\cline { 2 - 7 } & Fr & $\mathbf{\%}$ & Fr & $\mathbf{\%}$ & Fr & \% \\
\hline Bienestar psicológico & 3 & 1.0 & 140 & 47.1 & 154 & 51.9 \\
Aceptación / Control & 11 & 3.7 & 92 & 31.0 & 194 & 65.3 \\
Vínculos & 16 & 5.4 & 134 & 45.1 & 147 & 49.5 \\
Proyectos & 6 & 2.0 & 139 & 46.8 & 152 & 51.2 \\
Autonomía & 14 & 4.7 & 153 & 51.5 & 130 & 43.8 \\
\hline
\end{tabular}

Nota: $\mathrm{Fr}=$ Frecuencia. $\%=$ Porcentaje.

\section{Niveles de religiosidad}

De acuerdo a la tabla 2 el mayor porcentaje de los evaluados $(41.8 \%)$ se consideran parte de una religión, sin embargo, no asisten a misa regularmente ni participan activamente en alguna agrupación religiosa. Casi la cuarta parte de los evaluados (24.2\%) no cree en dios. Un 13.5\% mantiene la creencia en un ser superior pero sin vincularse a religión alguna. El menor porcentaje $(8.4 \%)$ acude a misa regularmente sin participar activamente 
en alguna agrupación religiosa. Finalmente, es el $12.1 \%$ que mantiene el mayor grado de involucramiento religioso, puesto que se considera parte de una religión, va a misa regularme y a la vez participa activamente en una agrupación religiosa.

Tabla 2

Distribución de la muestra según forma de involucramiento religioso

\begin{tabular}{lcc}
\hline & Frecuencia & Porcentaje \\
\hline No cree en dios & 72 & 24.2 \\
Solamente cree en dios & 40 & 13.5 \\
Pertenece a una religión & 124 & 41.8 \\
Va a misa regularmente & 25 & 8.4 \\
Participa activamente & 36 & 12.1 \\
Total & 297 & 100.0 \\
\hline
\end{tabular}

Nota: $\mathrm{Fr}=$ Frecuencia, $\%=$ Porcentaje.

De los datos de la tabla 2, se elaboraron niveles de involucramiento religioso. En ese sentido, el $24.2 \%$, se categoriza como ausencia de involucramiento religioso (no creen en dios).El involucramiento religioso medio queda conformado por quienes solamente creen en dios, pertenecen a una religión y van a misa regularmente, constituyendo el63.6\%. Finalmente el alto involucramiento religioso se conforma por el $12.1 \%$, que coincide con quienes además de creer en dios, pertenecer a una religión e ir a misa regularmente, también participan activamente en algún grupo religioso.

\section{Relación entre el nivel de involucramiento religioso y el nivel de bienestar psicológico y sus componentes en estudiantes universitarios}

La tabla 3muestra la correlación entre el nivel de religiosidad con el nivel de bienestar psicológico y sus cuatro componentes, al respecto se observa que los valores p son mayores a 0.05 en todos los casos, por lo cual el nivel de religiosidad es independiente del bienestar psicológico y de sus dimensiones. Sin embargo, se puede observar que en el caso de la dimensión de proyectos, si bien el valor $\mathrm{p}$ es mayor a 0.05 , es cercano a este (0.067).

Tabla 3

Correlación entre el nivel de involucramiento religioso y el nivel de bienestar psicológico y sus dimensiones

\begin{tabular}{lcccccc}
\hline & & $\begin{array}{c}\text { Bienestar } \\
\text { psicológico }\end{array}$ & $\begin{array}{c}\text { Aceptación } \\
\text { / Control }\end{array}$ & Vínculos & Proyectos & Autonomía \\
\hline \multirow{3}{*}{ Involucramiento religioso } & Rho & -.010 & -.065 & .043 & .106 & -.011 \\
& $\mathrm{P}$ & .862 & .265 & .460 & .067 & .844 \\
& $\mathrm{n}$ & 297 & 297 & 297 & 297 & 297 \\
\hline
\end{tabular}

Nota: Rho = coeficiente de correlación de Spearman. $\mathrm{P}=$ nivel de significancia para cada correlación. $\mathrm{n}=$ tamaño de la muestra 


\section{Diferencias en el bienestar psicológico y sus dimensiones según los niveles de involucramiento religioso en estudiantes universitarios}

En la tabla 4 se presentan las diferencias en cuanto al bienestar psicológico y sus dimensiones según el nivel de involucramiento religioso. Se observa una diferencia estadísticamente significativa según el nivel de involucramiento religioso en la dimensión proyectos $(\mathrm{p}=0.049)$, siendo el grupo de alto involucramiento religioso que obtiene el rango promedio mayor (179.01), mientras que el grupo con ausencia de involucramiento religioso obtiene el rango promedio menor (142.89). Es decir, son los evaluados que mantienen más alto involucramiento religioso los que presentan mayor bienestar psicológico en cuanto a la percepción de propósito y significado de su vida.

Tabla 4

Diferencias en el bienestar psicológico y sus dimensiones según nivel de involucramiento religioso mediante la prueba Kruskal Wallis

\begin{tabular}{|c|c|c|c|c|c|}
\hline Variable & Nivel de Involucramiento religioso & $\mathbf{n}$ & Rango promedio & Kruskal-Wallis & $\mathbf{P}$ \\
\hline \multirow{4}{*}{$\begin{array}{l}\text { Bienestar } \\
\text { psicológico }\end{array}$} & Ausencia & 72 & 153.63 & \multirow{4}{*}{5.533} & \multirow{4}{*}{.063} \\
\hline & Medio & 189 & 141.85 & & \\
\hline & Alto & 36 & 177.28 & & \\
\hline & Total & 297 & & & \\
\hline \multirow{4}{*}{$\begin{array}{l}\text { Aceptación / } \\
\text { Control }\end{array}$} & Ausencia & 72 & 161.60 & \multirow{4}{*}{3.523} & \multirow{4}{*}{.172} \\
\hline & Medio & 189 & 143.28 & & \\
\hline & Alto & 36 & 153.83 & & \\
\hline & Total & 297 & & & \\
\hline \multirow{4}{*}{ Vínculos } & Ausencia & 72 & 146.03 & \multirow{4}{*}{1.279} & \multirow{4}{*}{.527} \\
\hline & Medio & 189 & 147.48 & & \\
\hline & Alto & 36 & 162.89 & & \\
\hline & Total & 297 & & & \\
\hline \multirow{4}{*}{ Proyectos } & Ausencia & 72 & 142.89 & \multirow{4}{*}{6.030} & \multirow{4}{*}{.049} \\
\hline & Medio & 189 & 145.61 & & \\
\hline & Alto & 36 & 179.01 & & \\
\hline & Total & 297 & & & \\
\hline \multirow{4}{*}{ Autonomía } & Ausencia & 72 & 156.32 & \multirow{4}{*}{3.719} & \multirow{4}{*}{.156} \\
\hline & Medio & 189 & 142.63 & & \\
\hline & Alto & 36 & 167.81 & & \\
\hline & Total & 297 & & & \\
\hline
\end{tabular}

Nota: $\mathrm{P}=$ nivel de significancia para la comparación de los niveles de involucramiento religioso. $\mathrm{n}=$ tamaño de la muestra

\section{Diferencias en el bienestar psicológico y sus dimensiones según las variables asociadas al involucramiento religioso}

En cuanto a las diferencias en el bienestar psicológico y sus dimensiones de acuerdo a cada variable asociada al involucramiento religioso, se observa una diferencia estadísticamente significativa en el componente proyectos según asistencia a misa $(\mathrm{p}=0.048)$, presentando mayor rango promedio 
quienes sí asisten (164.02), así, son los evaluados que asisten a misa o reuniones religiosas quienes muestran mayor bienestar psicológico en cuanto a la percepción de propósito y significado de su vida. Además, se observa una diferencia estadísticamente significativa según participación activa en grupos religiosos en el bienestar psicológico $(\mathrm{p}=0.033)$ y en el componente proyectos $(\mathrm{p}=0.015)$, con un rango promedio mayor en el grupo de quienes sí participan, así, quienes participan activamente muestran mayor bienestar psicológico general y en cuanto a la percepción de propósito y significado de su vida.

\section{Tabla 5}

Diferencias en el bienestar psicológico y sus dimensiones según las variables asociadas al involucramiento religioso mediante la U de Mann Whitney

\begin{tabular}{llccccc}
\hline & & $\begin{array}{c}\text { Bienestar } \\
\text { psicológico }\end{array}$ & $\begin{array}{c}\text { Aceptación } \\
\text { / Control }\end{array}$ & Vínculos & Proyectos & Autonomía \\
& & & & & \\
& Rango promedio (Sí) & 147.52 & 144.97 & 149.95 & 150.96 & 146.66 \\
Creencia en dios & Rango promedio (No) & 153.63 & 161.60 & 146.03 & 142.89 & 156.32 \\
& U de Mann Whitney & 7767 & 7192.5 & 7886.5 & 7660 & 7573 \\
& P & .596 & .090 & .715 & .449 & .377 \\
Pertenencia a & Rango promedio (Sí) & 150.19 & 146.96 & 147.69 & 153.33 & 148.08 \\
religión & Rango promedio (No) & 147.03 & 152.38 & 151.16 & 141.84 & 150.52 \\
& U de Mann Whitney & 10139 & 9982 & 10118.5 & 9558.5 & 10189.5 \\
Asistencia a & P & .756 & .532 & .715 & .222 & .800 \\
misa & Rango promedio (Sí) & 164.02 & 143.21 & 152.88 & 166.75 & 165.33 \\
& Rango promedio (No) & 145.12 & 150.50 & 148.00 & 144.41 & 144.78 \\
& U de Mann Whitney & 6281.5 & 6845 & 6961.5 & 6115 & 6202 \\
Participa & P & .121 & .484 & .668 & $\mathbf{. 0 4 8}$ & .077 \\
activamente & Rango promedio (Sí) & 177.28 & 153.83 & 162.89 & 179.01 & 167.81 \\
& Rango promedio (No) & 145.10 & 148.33 & 147.08 & 144.86 & 146.41 \\
\hline & U de Mann Whitney & 3680 & 4524 & 4198 & 3617.5 & 4021
\end{tabular}

Nota: $\mathrm{P}=$ nivel de significancia para la comparación de categorías Sí y No.Rango promedio (Sí) = rango promedio de la categoría Sí de la variable respectiva. Rango promedio $(\mathrm{No})=$ rango promedio de la categoría NO de la variable respectiva.

\section{Comparación del grupo de participación activa en grupos religiosos con otras formas de involucramiento religioso en el bienestar psicológico y sus dimensiones}

La tabla 6 muestra la comparación del grupo de evaluados que participa activamente con los demás grupos. Así, se observan diferencias estadísticamente significativas en el bienestar psicológico, entre quienes participan activamente con los grupos de quienes únicamente creen en $\operatorname{dios}(\mathrm{p}=0.039)$ y quienes pertenece a alguna religión pero no asisten a misa regularmente $(\mathrm{p}=0.033)$, siendo los rangos promedio mayores para el grupo de participación activa, reflejando que este grupo mantiene mayor 
bienestar psicológico. Además, se observan diferencias estadísticamente significativas en el componente proyectos, entre quienes participan activamente con los grupos de quienes no creen en dios $(p=0.022)$, únicamente creen en dios pero no se afilian a alguna religión $(\mathrm{p}=0.032)$ $\mathrm{y}$ que pertenecen a alguna religión pero no asisten a misa regularmente $(p=0.026)$, con rangos promedio mayores para el grupo de participación activa, siendo este grupo el que mantiene mayor bienestar psicológico en la percepción de propósito y significado de su vida.

Tabla 6

Comparación del grupo de participación activa con otras formas de involucramiento religiosos en cuanto al bienestar psicológico y sus dimensiones

\begin{tabular}{llccccc}
\hline & & $\begin{array}{c}\text { Bienestar } \\
\text { psicológico }\end{array}$ & $\begin{array}{c}\text { Aceptación } \\
\text { / Control }\end{array}$ & Vínculos & Proyectos & Autonomía \\
& & & & & & \\
Participa & Rango promedio (PA) & 60.33 & 52.46 & 58.53 & 63.28 & 57.25 \\
activamente - No & Rango promedio (NCD) & 51.58 & 55.52 & 52.49 & 50.11 & 53.13 \\
cree en dios & U de Mann Whitney & 1086 & 1222.5 & 1151 & 980 & 1197 \\
& P & .165 & .546 & .302 & .022 & .484 \\
Participa & Rango promedio (PA) & 43.93 & 41.04 & 38.90 & 43.60 & 42.13 \\
activamente - Sí & Rango promedio (SCD) & 33.61 & 36.21 & 38.14 & 33.91 & 35.24 \\
cree en dios & U de Mann Whitney & 524.5 & 628.5 & 705.5 & 536.5 & 589.5 \\
& P & .039 & .271 & .866 & .032 & .145 \\
Participa & Rango promedio (PA) & 94.83 & 82.58 & 87.94 & 94.17 & 92.58 \\
activamente & Rango promedio (PAR) & 76.34 & 79.90 & 78.34 & 76.53 & 76.99 \\
- Pertenece a & U de Mann Whitney & 1716 & 2157 & 1964 & 1740 & 1797 \\
alguna religión & P & .033 & .715 & .235 & .026 & .059 \\
Participa & Rango promedio (PA) & 33.68 & 33.25 & 33.01 & 33.47 & 31.35 \\
activamente- & Rango promedio (AMR) & 27.14 & 27.76 & 28.10 & 27.44 & 30.50 \\
Asiste a misa & U de Mann Whitney & 353.5 & 369 & 377.5 & 361 & 437.5 \\
regularmente & P & .151 & .172 & .244 & .130 & .840 \\
\hline
\end{tabular}

Nota: $\mathrm{P}=$ nivel de significancia para la comparación de la categoría de Participación Activa con cada una de las otras formas de involucramiento religioso. Categorías: $\mathrm{PA}=$ Participa activamente, $\mathrm{NCD}=$ No cree en dios, $\mathrm{SCD}$ $=$ sí cree en dios, $\mathrm{PAR}=$ Pertenece a alguna religión, $\mathrm{AMR}=$ Asiste a misa regularmente.

\section{DISCUSIÓN}

A nivel descriptivo la mayor proporción de universitarios presentan alto nivel de bienestar psicológico, asimismo, es el componente aceptación/control, el que presenta la mayor proporción en el nivel alto, predominando el bienestar psicológico como aceptación de uno mismo, autocompetencia y percepción de control sobre las situaciones. Esto coincide con Barrantes y Ureña (2015) en universitarios de Costa Rica, quienes también hallaron niveles elevados en esta variable. Al igual que Freire (2014) en universitarios españoles. Similar resultado fue hallado por Zubieta y Delfino (2010) en estudiantes universitarios de Buenos Aires. Estos resultados se han venido atribuyendo a características como la 
juventud, la expectativa de que mediante la educación superior puedan acceder a mayor posibilidad de desarrollo posterior, así como, un mayor reconocimiento de parte de sus pares y la sociedad.

Respecto a la variable involucramiento religioso, un $24.2 \%$ no cree en dios, este porcentaje es mayor al encontrado en estudiantes universitarios españoles por García y Pérez (2005), donde la no creencia bordea el 16\%, asimismo, en ese mismo estudio el porcentaje de los considerados católicos practicantes es $19.8 \%$, similar al encontrado en la presente investigación donde, entre quienes van a misa regularmente y quienes participan activamente llegan a 20.5\%. Luengas (2010) quien estudió a estudiantes universitarios de México D.F., encontró que el 6.0\% manifiesta no tener ninguna convicción religiosa, porcentaje menor al $24.2 \%$ hallado, sin embargo, quienes afirman tener ciertas convicciones religiosas son el $13.2 \%$, dicho grupo es equiparable a quienes únicamente creen en dios pero no profesan religión alguna, que en el presente estudio son el 13.5\%, mostrando similitud. En Perú, de acuerdo al último censo en 2007el Instituto Nacional de Estadística e Informática [INEI] (2008) reporta que un $2.9 \%$ de la población general no asume ninguna religión, sin embargo, en un estudio más reciente de la Compañía Peruana de Estudios de Mercado y Opinión Pública [CPI] (2014) en población urbana, encuentra que entre los 18 a 24 años el 9.1\% de los encuestados no profesan ninguna religión. Si bien este dato es más cercano a la muestra de estudio, aún así, es menos de la mitad del porcentaje encontrado. Cabe agregar que en esta encuesta el $15.9 \%$ se encuentran muy comprometidos con su religión, lo cual es equiparable al $12.1 \%$ que mantiene una participación activa en grupos religiosos.

De lo anteriormente descrito se derivan dos tendencias, una hacia menor creencia en dios y otra hacia formas alternativas de espiritualidad a las religiones tradicionales. Luengas (2010) menciona que en el caso de los jóvenes se viene dando un proceso de religión a la carta, en su perspectiva, dado que la persona presenta necesidad por lo sagrado opta por formas religiosas no tradicionales, lo que concuerda con que un $13.5 \%$ de los evaluados afirmen creer en un dios, pero que no se adscriban a una religión en particular. Asimismo, Mendoza y De la Hoz (2013) afirman que, en el caso de los estudiantes universitarios existe influencia de dinámicas sociales y académicas que los hacen dudar o cambiar sus creencias religiosas, ya sea por la idea de libertad que el ambiente inspira o por la interacción que tienen con los docentes y sus planteamientos, además, los universitarios son conscientes de la probable mutabilidad que puede tener sus creencias religiosas a lo largo de sus vidas.

En el análisis inferencial no se encontró relación significativa entre involucramiento religioso y bienestar psicológico. Si bien existe respaldo a la hipótesis planteada, algunos autores manifiestan que la religiosidad presenta cierta dualidad al respecto. Cyrulnik (2002) percibe a la religión como algo positivo, pero 
indica que una adaptación excesiva no es beneficiosa cuando implica sumisión o renuncia a uno mismo. Además, Drakeford (1980) considera como formas de perversión de la religión, el evadir la realidad, evitar las consecuencias de las faltas y cierto narcisismo. También, se han mantenido la tendencia a distinguir entre dos religiosidades, una saludable y otra negativa. Fromm (1947) plantea una religión autoritaria y otra humanística, mientras que Allport (1986) diferencia entre extrínseca e intrínseca. Las primeras se acompañan de una conciencia moral inconstante y fragmentaria, mientras que en las últimas existe un sentimiento religioso maduro, acompañado de una conciencia genérica. Esta dualidad no se ha considerado al proponer el involucramiento religioso, lo cual se recomienda para investigaciones posteriores.

Se ha caracterizado a los individuos con alto involucramiento religioso y de participación activa, a quienes se asumen como parte de una religión, asisten frecuentemente a misa y participan activamente en un grupo religioso. Este grupo presenta mayor bienestar psicológico en cuanto al componente proyectos, al compararse con los otros niveles de involucramiento religioso. Presentan mayor bienestar psicológico y en el componente proyectos al compararse con quienes no participan activamente en algún grupo religioso. Presentan mayor bienestar psicológico al ser comparado con quienes solamente creen en dios sin afiliarse a alguna religión, y frente a quienes se asumen como parte de una religión pero no asisten a misa regularmente. Y finalmente, muestran mayor puntuación en el componente proyectos frente a quienes no creen en dios, quienes creen en dios sin afiliarse a alguna religión y quienes pertenecen a alguna religión pero no asisten a misa con regularidad. Por lo anterior, el aspecto terminante que establece distinción en el bienestar psicológico, es la participación activa en actividades religiosas y la forma de expresión del bienestar psicológico con la cual la participación activa logra mayor relación es la descrita en el componente proyectos, es decir el bienestar como la percepción de propósito y significado de la vida.

Lo primero coincide con Martínez (2014) en jóvenes católicos de Lima Norte, quien halló asociaciones positivas entre áreas involucradas en las prácticas religiosas con el bienestar subjetivo, en el mismo sentido, los jóvenes que se consideran católicos practicantes muestran mayor satisfacción con la vida, en la medida que presentan más prácticas religiosas. Dasso (2010) en internas de un penal de mujeres en Lima, halló una relación inversa entre sintomatología depresiva y las prácticas religiosas de comportarse como dios espera, leer la biblia y cantar a dios como forma de oración. Vargas y Martínez (2015) en adolescentes mexicanos encontraron que ser parte de una red social que asiste a la iglesia y valorarla, constituyen factores protectores contra el alcoholismo. Al respecto, Yoffe (2012) menciona que participaren redes sociales religiosas se ha asociado a diferentes tipos de estrategias de afrontamiento de problemas que reducen el riesgo de estrés, 
asimismo, la meditación como distintas formas de plegarias religiosas producen reacciones favorables como el fortalecimiento del sistema inmunológico.

De otro lado, García, Martínez, Sellés y Soucase (2013) en universitarios españoles hallaron una relación significativa y positiva entre sentido de la vida y orientación religiosa intrínseca, donde la religión es un fin en sí misma y es el criterio absoluto para las decisiones ,al respecto, Milanesi y Aletti (1974; citados por García et al., 2013) afirman que la religiosidad se halla estrechamente ligada a la búsqueda global de significado de la existencia y un horizonte desde donde orientar la vida. Similar resultado obtuvieron Avellar de Aquino, et al. (2009) en residentes de Campina Grande, encontrando asociación positiva entre el sentido de la vida y la actitud religiosa, señalando que creer en algo superior es una forma de encontrar sentido a la relación entre el sujeto y el mundo, y puede proveer una visión más optimista, al interpretar la existencia como una misión. Complementando, Mafla (2013) señala que la religión en cuanto a lo psicológico cumple la función de poder y sentido, señalando que para las personas religiosas, el creer en dios implica plantearse la pregunta sobre el sentido de la vida y creer haberlo encontrado, además que este sentido parte de uno mismo y no es infundido desde el exterior.

Finalmente, de los resultados hallados se puede señalar que si bien en la muestra total no se encuentra una relación significativa entre el bienestar psicológico y el involucramiento religioso, en un acercamiento más específico, es el grupo que presenta mayor involucramiento religioso, es decir, el que mantiene participación activa en grupos religiosos, el que muestra mayor bienestar psicológico en comparación con las demás formas y niveles de involucramiento religioso, y además este bienestar es más evidente en cuanto a la percepción de propósito y significado de la vida.

\section{CONCLUSIONES}

1. En un análisis descriptivo, cerca de la mitad de los estudiantes presentan alto bienestar psicológico, asimismo predomina el bienestar psicológico como aceptación de uno mismo, el sentido de autocompetencia y el control sobre las situaciones.

2. La cuarta parte de los estudiantes presenta ausencia de involucramiento religioso, mientras que poco más de la décima parte de ellos muestra alto involucramiento religioso, lo que implica que asisten a misa con regularidad y mantienen una participación activa en grupos religiosos.

3. A nivel general no se encuentra relación entre los niveles de bienestar psicológico y los niveles de involucramiento religioso. 
4. Existe diferencia significativa según el nivel de involucramiento religioso en la dimensión proyectos, siendo mayor en el grupo de alto involucramiento religioso. Así, son los evaluados con alto involucramiento religioso los que presentan mayor bienestar psicológico en cuanto a la percepción de propósito y significado de su vida.

5. Existe diferencia significativa según participación activa en grupos religiosos en el bienestar psicológico general y en la dimensión proyectos con un rango promedio mayor en el grupo de participación activa. Así, son los evaluados que participan activamente quienes muestran mayor bienestar psicológico general y en cuanto a la percepción de propósito y significado de su vida.

6. Existen diferencias significativas en el bienestar psicológico general, entre quienes participan activamente en grupos religiosos con los grupos de quienes únicamente creen en dios pero no se afilian a alguna religión y quienes pertenece a alguna religión, siendo mayor en el grupo de participación activa, así, es este grupo el que mantiene mayor bienestar psicológico.

7. Existen diferencias significativas en la dimensión proyectos, entre quienes participan activamente en grupos religiosos con los grupos de quienes no creen en dios, quienes únicamente creen en dios pero no se afilian a alguna religión y quienes pertenece a alguna religión, siendo mayor en el grupo de participación activa, así, es este grupo el que mantiene mayor bienestar psicológico en cuanto a la percepción de propósito y significado de su vida.

\section{REFERENCIAS BIBLIOGRÁFICAS}

Allport, G. (1986). La personalidad: su configuración y desarrollo. 8va Ed. Barcelona:Herder.

Arias, W., Masías, M., Muñoz, E. y Arpasi, M. (2013). Espiritualidad en el ambiente laboral y su relación con la felicidad del trabajador. Revista de investigación de la Universidad Católica San Pablo, Volumen 4, 9 - 33. Recuperado de: http://ucsp.edu. pe/images/direccion_de_investigacion/PDF/revista2013/Espiritualidad-y-felicidaden-el-trabajador.pdf

Avellar de Aquino, T., Pereira, A., Camara, A., De Souza, C., De Assis, H., Ferreira, I., Dos Santos, P. y Fernandes, W. (2009). Atitude religiosa e sentido da vida: umestudo correlacional. Psicologiaciência e profissão, 29 (2), 228-243. Recuperado de: http:// www.redalyc.org/pdf/2820/282021772003.pdf

Barrantes, K. y Ureña, P. (2015). Bienestar psicológico y bienestar subjetivo en estudiantes universitarios costarricenses. Revista Intercontinental de Psicología y Educación, 17 (1), 101 - 123. Recuperado de: http://www.redalyc.org/pdf/802/80242935006.pdf 
Castro, A. (2009). El bienestar psicológico: cuatro décadas de progreso. Revista Interuniversitaria de Formación del Profesorado, 66 (23), 43-72. Recuperado de: http://www.aufop.com/aufop/uploaded_files/articulos/1258587233.pdf

Casullo, M. (2002). Evaluación del bienestar psicológico en Iberoamérica. Paidos: Buenos Aires.

Casullo, M. y Castro, A. (2000). Evaluación del bienestar psicológico en estudiantes argentinos. Revista de Psicología de la PUCP, 28 (1), 35 - 68. Recuperado de: http:// dialnet.unirioja.es/descarga/articulo/4531342.pdf

Ceballos, G., Pérez, K., Rosado, A. y Rodríguez, R. (2014). Religiosidad y comportamientos de riesgo para la salud: un estudio transversal con estudiantes de una universidad pública de Santa Marta (Colombia). Revista Escenarios, 12 (2), 53-63. Recuperado de: http://repositorio.uac.edu.co/bitstream/handle/11619/1398/ Religiosidad\%20y\%20comportamientos\%20de\%20riesgo\%20para\%20la\%20salud. pdf? sequence $=1 \&$ isAllowed $=\mathrm{y}$

Compañía Peruana de Estudios de Mercado y Opinión Pública [CPI] (2014). Estudio de opinión pública sobre religión. Recuperado de: http://cpi.pe/images/upload/ paginaweb/archivo/23/OPNAC201407_01.pdf

Cyrulnik, B. (2002). Los patitos feos. La resiliencia. Una infancia infeliz no determina la vida. Barcelona: Gedisa

Dasso, A. (2010). Sintomatología depresiva y prácticas religiosas en internas por delitos comunes de un penal de Lima.Tesis de Licenciatura en psicología, Pontificia Universidad Católica del Perú. Recuperado de: http://tesis.pucp.edu. pe/repositorio/bitstream/handle/123456789/659/DASSO_VASSALLO_ANA_ SINTOMATOLOG\%C3\%8DA.pdf?sequence $=1$

Díaz, D., Rodríguez, R., Blanco, A., Moreno, B., Gallardo, I., Valle, C. y Van Dierendonck (2006). Adaptación española de la escala de bienestar psicológico de Ryff. Psicothema, 18 (3), 572 - 577. Recuperado de: http://www.psicothema.com/pdf/3255.pdf

Domínguez, S. (2014). Análisis psicométrico de la escala de bienestar psicológico para adultos en estudiantes universitarios de lima: un enfoque de ecuaciones estructurales. Pychologia: avances de la disciplina, 8 (1), 23 - 31. Recuperado de:http://www.uigv. edu.pe/fileadmin/facultades/psicologia/documentos/2014_Bienestar_Psicologico Universitarios.pdf

Drakeford, J. (1980). Psicología y Religión. Buenos Aires: Bautista Publicaciones.

Ferre, Z., Gerstenblüth, M. y Rossi, M. (2008). Satisfacción con la vida, fe religiosa y asistencia al templo en Uruguay. Recuperado de: http://www.ugr.es/ teoriahe/ RePEc/gra/paoner/per10_01.pdf

Florenzano, R. (2010). Religiosidad y salud mental: amigos o enemigos. Revista psiquiatría universitaria, 6 (2), 221 - 229. Recuperado de:http://revistagpu.cl/GPU\%202\%20 (2010)/REF\%20Religiosidad.pdf

Freire, C. (2014). El bienestarpsicológico en los estudiantes universitarios: Operativización del constructo y análisis de su relación con las estrategias de afrontamiento. 
Tesis Doctoral en Salud, Discapacidad y Dependencia. Universidad La Coruña, España. Recuperado de: http://ruc.udc.es/dspace/bitstream/handle/2183/13815/ FreireRodriguez_Carlos_TD_2014.pdf?sequence $=6$

Fromm, E (1947). Ética y psicoanálisis. México D.F.: Fondo de cultura económica.

Garcés, J. (1985). Perspectivas actuales en psicología de la religión. Estudios de psicología, $\mathrm{N}^{\circ} 23$ - 24, 187 - 198. Recuperado de: http://dialnet.unirioja.es/descarga/ articulo/65948.pdf

García, J. y Pérez, E. (2005). Actitudes religiosas y valores en un grupo de jóvenes universitarios españoles. Revista Anales de Psicología, 21 (1), 149 - 169. Recuperado de: http://www.um.es/analesps/v21/v21_1/15-21_1.pdf

García, J., Martínez, E., Sellés, P. y Soucase, B. (2013). Orientación religiosa y sentido de vida. UniversitasPsychologica, 12 (3), 363 - 374. Recuperado de: http://www. redalyc.org/pdf/647/64728763005.pdf

González, C. (2004). La psicología positiva: un cambio en nuestro enfoque patológico clásico. Revista de Psicología Liberabit, $\mathrm{N}^{\circ}$ 10, 82-88. Recuperado de: http://www. redalyc.org/pdf/686/68601009.pdf

Griffa, M. y Moreno, J. (1999). Claves para una Psicología del desarrollo. Buenos Aires, Argentina: Lugar editorial.

Hernández, R., Fernández, C. y Baptista, P. (2014). Metodología de la investigación cientifica. 6ta Ed. Mac Graw Hill: México D.F.

Instituto Nacional de Estadística e Informática [INEI] (2008). Censos Nacionales 2007: XI de Población y VI de Vivienda. Perfil sociodemográfico del Perú. Recuperado de: https://www.inei.gob.pe/media/MenuRecursivo/publicaciones_digitales/Est/ Lib1136/libro.pdf

Jiménez, J. (2005). La espiritualidad, dimensión olvidada de la medicina. Gaceta universitaria, $\mathrm{N}^{\circ} 1,92$ - 101. Recuperado de: http://revistagpu.cl/2005/ GPU_junio_2005_PDF/LA\%20ESPIRITUALIDAD\%20DIMENSION\%20 OLVIDADA\%20DE\%20LA\%20MEDICINA.pdf

Luengas, E. (2010). Los jóvenes universitarios y su religiosidad en la UIA Plantel León. Estudio de caso para obtener el grado de Maestra en Teología y Mundo Contemporáneo. Universidad Iberoamericana, México. Recuperado de: http://www. bib.uia.mx/tesis/pdf/015304/015304.pdf

Mafla, N. (2013). Función de la religión en la vida de las personas según la psicología de la religión. TheologicaXavierana, 63 (176), 429 - 459. Recuperado de: http://www. redalyc.org/pdf/1910/191029949006.pdf

Martínez, M. (2014). Religiosidad, Prácticas Religiosas y Bienestar Subjetivo en Jóvenes Católicos de Lima Norte. Tesis para optar por el título profesional de Licenciada en Psicología con mención en Psicología Social. Pontificia Universidad Católica del Perú, Perú. Recuperado de: http://tesis.pucp.edu.pe/repositorio/handle/123456789/5432

Mendoza E. y De la Hoz, I. (2013). Elementos que influyen en la definición de las creencias religiosas de los estudiantes de historia de la Universidad de Cartagena. 
Proyecto de grado para optar el título profesional de comunicación social. Universidad de Cartagena, Colombia. Recuperado de: http://190.242.62.234:8080/ jspui/bitstream/11227/1034/1/tesis\%20erika.pdf

Nervi, M. (2011). Espiritualidad, Religiosidad y Bienestar. Una aproximación empírica a las diferencias entre espiritualidad y religiosidad y su relación con otras variables. Reduciendo la controversia. Revista Psicología.com. Recuperado de: http://hdl. handle.net/10401/4709

Quiceno, J. y Vinaccia, S. (2009). La salud en el marco de la psicología de la religión y la espiritualidad. Revista diversitas - Perspectivas en psicología, 5 (2), 321 - 336. Recuperado de: http://www.redalyc.org/pdf/679/67916260008.pdf

Reyes, M., Rivera, E., Ramos, A., Rosario, E. y Rivera, C. (2014). Desarrollo yvalidación de una escala para medirreligiosidad en unamuestra de adultos en Puerto Rico. Revista Puertorriqueña de Psicología, 25 (2), 226 - 242. Recuperado de: https:// dialnet.unirioja.es/servlet/articulo?codigo $=4895945$

Rodríguez, M., Fernández, M., Pérez, M. y Noriega, R. (2011). Espiritualidad variable asociada a la resiliencia. Cuadernos hispanoamericanos de psicología, 11 (2), 24 - 49.Recuperado de: http://www.uelbosque.edu.co/sites/default/files/publicaciones/ revistas/cuadernos_hispanoamericanos_psicologia/volumen11_numero2/articulo_2. pdf

Romero, A., García, A. y Brustad, R. (2009). Estado del arte, y perspectiva actual delconcepto de bienestar psicológico en psicología del deporte. Revista Latinoamericana de Psicología, 41 (2), 335 - 347. Recuperado de: http://www. redalyc.org/pdf/805/80511496011.pdf

Salgado, A. (2014). Revisión de estudios empíricos sobre el impacto de la religión, religiosidady espiritualidad como factores protectores. Propósitos y Representaciones, 2 (1), 121 - 140. Recuperado de: http://repositorio.usil.edu. pe/bitstream/123456789/1568/3/2014_Salgado_Revisi\%C3\%B3n\%20de\%20 estudios $\% 20$ emp $\%$ C3\%ADricos $\% 20$ sobre $\% 20$ el $\% 20$ impacto $\% 20$ de $\% 201$ a $\% 20$ religi $\%$ C3\%B3n $\% 20$ religiosidad $\% 20 \mathrm{y} \% 20$ espiritualidad $\% 20$ como $\% 20$ factores $\% 20$ protectores.pdf

Sardín, M. (2012). La importancia de la religión para el desarrollo. Un análisis empírico a partir de la ecuación de Mincer. Ensayos de Política Económica, 1 (6), 77 - 119. Recuperado de: http://bibliotecadigital.uca.edu.ar/repositorio/revistas/importanciareligion-desarrollo-sardin.pdf

Simkim, H. (2010). Ansiedad, depresión y religiosidad en población judia. Trabajo presentado en la conferencia del II Congreso Internacional de Investigación y Práctica Profesional en Psicología XVII Jornadas de Investigación Sexto Encuentro de Investigadores en Psicología del MERCOSUR. Universidad de Buenos Aires, Buenos Aires. Recuperado de: https://www.aacademica.org/hugo.simkin/4.pdf

Uresti, R., Ramírez, J. y Caballero, F. (2011). Salud y espiritualidad: no solo de pan vive el hombre. Ciencia UAT, 6 (2), 48 - 54. Recuperado de: http://www.redalyc.org/ pdf/4419/441942926002.pdf 
Valiente, C. (2013). Intersecciones entre espiritualidad/religiosidad y psicología: desde la filosofía hasta la neurociencia. Revista de historia de la psicología, 34 (4), 67 - 88. Recuperado de: http://www.actiweb.es/lumen/archivo4.pdf

Valiente, C. y García, E. (2010). Aspectos neurológicos relativos a estados alterados de conciencia asociados a la espiritualidad. Revista de Neurología, 51 (4), 226 236. Recuperado de: http://pendientedemigracion.ucm.es/centros/cont/descargas/ documento25316.pdf

Vargas, E. y Martínez, G. (2015). La relación entre el abuso del alcohol y la religión en adolescentes mexicanos. Revista electrónica Población y salud en Mesoamérica, 12 (2), 1 - 22. Recuperado de: http://revistas.ucr.ac.cr/index.php/psm/article/ viewFile/16783/17203

Vielma, J. y Alonso, L. (2010). El estudio del bienestar psicológico subjetivo. Una breve revisión teórica. EDUCERE: Artículos arbitrarios, 14 (49), 265 - 275. Recuperado de: http://www.saber.ula.ve/bitstream/123456789/32748/1/articulo2.pdf

Yoffe, L. (2012). Beneficios de las prácticas religiosas/espirituales en el duelo. Avances en Psicología, 20 (1), 9-30. Recuperado de: http://www.unife.edu.pe/pub/revpsicologia/ avances2012/laurayoffe.pdf

Zubieta, E. y Delfino, G. (2010). Satisfacción con la vida, bienestar psicológico y bienestar social en estudiantes universitarios de Buenos Aires. Revista de la Facultad de Psicología de la UBA, 17, 277 - 283. Recuperado de: http://www.scielo.org.ar/pdf/ anuinv/v17/v17a27.pdf 